\title{
Can we get a clue for the etiology of Kawasaki disease in the COVID-19 pandemic?
}

Jong-Woon Choi, MD, PhD*

Department of Pediatrics, Bundang Jesaeng General Hospital, Daejin Medical Center, Seongnam, Korea

\section{Key message}

A new coronavirus disease 2019 (COVID-19) has been spreading globally since December 2019. Children with a Kawasaki disease (KD)-like illness related with COVID-19 have been reported in Europe and the United States. They presented with symptoms of KD with or without cardiac abnormalities or shock, showing manifestations of hyperactive proinflammatory cytokine reactions like KD. Such cases may provide the opportunity for us to learn more about the etiology and pathogenesis of KD.

A new coronavirus disease 2019 (COVID-19) has been spreading globally since December 2019, and the number of total patients with COVID-19 reached 5 million in the world as of late May 2020. COVID-19, a highly contagious disease, occurred first in China, spread quickly to Korea, Japan, and southeast Asian countries, and finally reached Europe and the Americas, becoming a pandemic disease.

Children with a Kawasaki disease (KD)-like illness have been recently reported in Europe and the United States (US) during the COVID-19 pandemic. Such patients presented with fever, skin rash, conjunctivitis, oral mucosa changes (red fissured lips, strawberry tongue), and hand or foot edema, all of which are included in the diagnostic criteria for $\mathrm{KD}$, in addition to gastrointestinal symptoms (abdominal pain, vomiting, diarrhea). 1) Some of these patients also exhibited cardiac abnormalities (left ventricular dysfunction, myocarditis, pericarditis, valvular regurgitation, coronary arterial ectasia or aneurysm), that can be also observed in $\mathrm{KD}$, while others presented with symptoms of shock (hypotension, cold extremities, hypoxemia, consciousness change). More than half or two-thirds of these patients tested positive for COVID-19 on the polymerase chain reaction or antibody test. ${ }^{1,2)}$

KD was first reported by Dr. Tomisaku Kawasaki in Japan in 1967. Since then, it has been reported worldwide, although its incidence rate varies among countries, races, and ethnicities. The incidence rate of $\mathrm{KD}$ is the highest in east Asian countries, including Japan, Korea, China, and Taiwan, and relatively low in western countries. Despite many clinical and experimental studies spanning decades, the etiology of $\mathrm{KD}$ remains unknown. However, its pathogenesis is explained by the theory of abnormal or dysregulated immune reactions. It has been postulated that one of pathogens (including viruses, bacteria, etc.), toxins, or environmental agents may trigger abnormal or dysregulated immune reactions in genetically susceptible children, leading to release of large amounts of proinflammatory cytokines, and causes KD manifesting systemic vasculitis. ${ }^{3)}$ So KD can be included within the spectrum of the cytokine storm syndrome. The reason why the etiology of $\mathrm{KD}$ has not been found out may be because the triggering or causative factor of KD may be not only one agent, but be multiple agents.

The KD-like illness related with COVID-19 was reported to develop 2-4 weeks after the peak of the COVID-19 pandemic in Europe and the US. This may be consistent with the fact that the incidence of $\mathrm{KD}$ shows annual and seasonal variations. Nationwide surveys in Korea and Japan and epidemiological studies in the US indicated that the incidence of KD peaks in the winter and early summer. ${ }^{3,4)}$ This is consistent with the observation that KD seems to be associated with antecedent respiratory illnesses and develop after epidemic periods of viral illnesses. ${ }^{3,5)}$

On the contrary, the age distribution of patients with the KD-like illness related with COVID-19 differs from that of KD patients. KD usually develops in infants and younger children, and is uncommon in older children more than 10 years of age; approximately $80 \%$ of $\mathrm{KD}$ patients are less than 5 years of age and about half are less than 2 years of age. ${ }^{3,4)}$ However, the KDlike illness related with COVID-19 usually developed after 1-2 years of age and was also common in children older than 10 years of age. ${ }^{1,2)}$ The incidence rate of KD is the highest in east Asian countries, and relatively low in western countries, which may reflect differences in races or environments. In contrast, the KD-like illness related with COVID-19 was most commonly reported in Europe and the US, and rarely reported in east Asian countries, although the incidence of COVID-19 was also high in east Asian countries. This might be due to the difference in

Corresponding author: Jong-Woon Choi, MD, PhD. Department of Pediatrics, Bundang Jesaeng General Hospital, 20 Seohyun-ro 180, Bundang-gu, Seongnam 13590, Korea 凶E-mail: cjw@dmc.or.kr, https://orcid.org/0000-0003-2246-6752

*The President of the Korean Society of Kawasaki Disease

Received: 25 May, 2020, Revised: 12 June, 2020, Accepted: 17 June, 2020

This is an open-access article distributed under the terms of the Creative Commons Attribution Non-Commercial License (http://creativecommons.org/licenses/by$\mathrm{nc} / 4.0 /$ ) which permits unrestricted non-commercial use, distribution, and reproduction in any medium, provided the original work is properly cited.

Copyright (c) 2020 by The Korean Pediatric Society 
genotypes of the COVID-19 virus.

We have not experienced a pandemic disease like COVID-19 until now. COVID-19 has spread globally in a short period of time, resulting in many cases in every country. Many people have undergone diagnostic testings, which has revealed its detailed epidemiological and clinical features. In addition, a KDlike illness occurred in children that seemed to be related with COVID-19. The occurrence of such cases may provide the opportunity for us to learn more about the etiology and pathogenesis of KD and analyze its relationship with COVID-19.

\section{Conflict of interest}

The author declares no potential conflict of interest relevant to this article.

\section{References}

1. Whittaker E, Bamford A, Kenny J, Kaforou M, Jones CE, Shah P, et al. Clinical characteristics of 58 children with a pediatric inflammatory multisystem syndrome temporally associated with SARS-CoV-2. JAMA 2020 Jun 8:e2010369. httsps://doi.org/10.1001/jama.2020.10369.

2. Belhadjer Z, Meot M, Bajolle F, Khraiche D, Legendre A, Abakka S, et al. Acute heart failure in multisystem inflammatory syndrome in children (MIS-C) in the context of global SARS-CoV-2 pandemic. Circulation 2020 May 17. httsps://doi.org/10.1161/CIRCULATIONAHA.120.048360.

3. McCrindle BW, Rowley AH, Newburger JW, Burns JC, Bolger AF, Gewitz $\mathrm{M}$, et al. Diagnosis, treatment, and long-term management of Kawasaki disease: a scientific statement for health professionals from the American Heart Association. Circulation 2017;135: e927-99.

4. Kim GB, Park SH, Eun LY, Han JW, Lee SY, Yoon KL, et al. Epidemiological and clinical features of Kawasaki disease in South Korea, 2012-2014. Pediatr Infect Dis J 2017;36:482-5.

5. Rowley AH, Shulman ST. The epidemiology and pathogenesis of Kawasaki disease. Front Pediatr 2018;6:374. 